\title{
Glutamine and ornithine alpha-ketoglutarate supplementation on malate dehydrogenases expression in hepatectomized rats ${ }^{1}$
}

\author{
Artur Guimarães Filho', Rodrigo Maranguape Silva da Cunha', Paulo Roberto Leitão de Vasconcelos ${ }^{\mathrm{III}}$, Sergio Botelho \\ Guimarães $^{\mathrm{IV}}$
}

DOI: http://dx.doi.org/10.1590/S0102-86502014000600003

IFellow PhD degree, Postgraduate Program in Surgery, Department of Surgery, Federal University of Ceara (UFC), Fortaleza-CE, Brazil. Conception and design of the study, technical procedures, acquisition and interpretation of data.

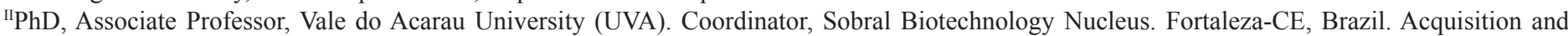
interpretation of data.

IIIPhD, Full Professor, Coordinator, Postgraduate Program in Surgery, Department of Surgery, UFC, Fortaleza-CE, Brazil. Interpretation of data, critical revision.

${ }^{\mathrm{IV}} \mathrm{PhD}$, Associate Professor, Department of Surgery. Head, Experimental Surgical Research Laboratory (LABCEX), UFC, Fortaleza-CE, Brazil. Conception, design, intellectual and scientific content of the study, manuscript writing, critical revision.

\section{ABSTRACT}

PURPOSE: To evaluate the relative gene expression (RGE) of cytosolic (MDH1) and mitochondrial (MDH2) malate dehydrogenases enzymes in partially hepatectomized rats after glutamine (GLN) or ornithine alpha-ketoglutarate (OKG) suplementation.

METHODS: One-hundred and eight male Wistar rats were randomly distributed into six groups ( $\mathrm{n}=18)$ : CCaL, GLNL and OKGL and fed calcium caseinate $(\mathrm{CCa})$, GLN and $\mathrm{OKG}, 0.5 \mathrm{~g} / \mathrm{Kg}$ by gavage, 30 minutes before laparotomy. CCaH, GLNH and OKGH groups were likewise fed 30 minutes before 70\% partial hepatectomy. Blood and liver samples were collected three, seven and 14 days after laparotomy/hepatectomy for quantification of MDH1/MDH2 enzymes using the real-time polymerase chain reaction (PCR) methodology. Relative enzymes expression was calculated by the $2^{-\Delta \Delta C}$ method using the threshold cycle $\left(\mathrm{C}_{\mathrm{T}}\right)$ value for normalization. RESULTS: MDH1/MDH2 RGE was not different in hepatectomized rats treated with OKG compared to rats treated with CCa. However, MDH1/MDH2 RGE was greater on days 3 (321:1/26.48:1) and 7 (2.12:1/2.48:1) while MDH2 RGE was greater on day 14 (7.79:1) in hepatectomized rats treated with GLN compared to control animals.

CONCLUSION: Glutamine has beneficial effects in liver regeneration in rats by promoting an up-regulation of the MDH1 and MDH2 relative gene expression.

Key words: Glutamine. Ornithine. Hepatectomy. Liver Regeneration. Polymerase Chain Reaction. Enzymes. Rats. 


\section{Introduction}

Potential mechanisms and pathways of liver regeneration have been extensively investigated in recent reviews ${ }^{1,2}$. Holecek ${ }^{3}$ studied the effects of carbohydrates, lipids, and amino acids on partial hepatectomy and concluded that administration of a standard amino acid mixture without energy substrate has an inhibitory effect on liver regeneration. Birkhahn et al. ${ }^{4}$ studies demonstrated that the inhibitory effect of glucose on liver regeneration can be diminished by the simultaneous administration of aminoacids and other substances.

Experimental studies have shown that ornithine alpha-ketoglutarate $(\mathrm{OKG})$ supplementation of enteral feeding significantly shortens wound healing time in severe burn patients ${ }^{5}$. It has been reported that OKG stimulates the production on insulin and growth hormone promoting intracellular aminoacid transport and protein synthesis ${ }^{6}$. Glutamine (GLN) is the most abundant amino acid in the circulation and the main source of nitrogen for various metabolic processes including purine and pyrimidine synthesis necessary for DNA replication and cellular proliferation ${ }^{7,8}$. Yoshida et al. ${ }^{8}$ treated partially hepatectomized rats with a parenteral solution containing GLN, resulting in increased uptake of the aminoacid by the hepatocytes and enterocytes and an increase in DNA and protein synthesis.

Two essential malate dehydrogenases, MDH1 (cytosolic malate dehydrogenase) and $\mathrm{MDH} 2$ (mitochondrial malate dehydrogenase), play important roles in the Krebs cycle for energy production through aerobic respiration ${ }^{9}$. MDH1 transports NADH equivalents across the mitochondrial membrane, controlling tricarboxylic acid (TCA) cycle pool size. MDH1 mRNA is expressed primarily in cardiac and skeletal muscle and in the brain, at intermediate levels in the spleen, kidney, intestine, liver, and testes and at low levels in lung and bone marrow ${ }^{10}$. MDH2 is the final enzyme in the mitochondrial tricarboxylic acid (TCA) cycle.
It catalyzes the inter-conversion of L-malate and oxaloacetate using nicotinamide adenine dinucleotide (NAD) as a cofactor to generate reducing equivalents ${ }^{11}$.

Considering the importance of MDH1 and MHD2 in the metabolic processes and the absence of specific studies of the role of these enzymes in hepatic regeneration, this study aims to evaluate the expression of MDH1 and MHD2 in an experimental partial hepatectomy model after administration of OKG and GLN.

\section{Methods}

Approval for experimental use of laboratory animals was obtained from the local Ethics Committee on Animal Use (CEUA, former CEPA) (protocol 54/08, 30 Sept 2008) and is in compliance with the Federal Law No. 11794 of October 8, 2008, and the Decree $n^{\circ} 6,689$, July 15, 2009 that regulated the law in 11,794, available at: http: www.planalto.gov.brccivil03Ato200720102008LeiL11794.htm. The study was designed to minimize the number of animals required for the experiments.

In this controlled experimental study, after one week of acclimatization, 36 adult male Wistar rats weighting 170-325g, provided by the Sobral Zoonosis Center Vivarium were used. Rats were kept in a climate controlled room under 12-hour light/ dark cycles with free access to food and tap water throughout the studies. Before the experiments the animals were randomly distributed into six groups $(\mathrm{n}=18)$ and treated (Table 1$)$ as follows: groups $\mathrm{CCaL}$, GLNL and OKGL were fed calcium caseinate (CCa), GLN and $\mathrm{OKG}, 0.5 \mathrm{~g} / \mathrm{Kg}$ by gavage, 30 minutes before laparotomy; the 3 remaining groups $(\mathrm{CCaH}, \mathrm{GLNH}$ and $\mathrm{OKGH})$ were likewise fed $\mathrm{CCa}, \mathrm{GLN}$ and $\mathrm{OKG}, 0.5 \mathrm{~g} / \mathrm{Kg}$ by gavage, 30 minutes before $70 \%$ partial hepatectomy. Next, each group was divided into three subgroups $(n=6)$ according to sample collection time (3, 7 and 14 days after laparotomy/hepatectomy) (Table 1).

TABLE 1 - Experimental groups and subgroups classified according to drugs used and surgical procedures.

\begin{tabular}{clllc}
\hline Groups & & Subgroups (n) & Drugs and Procedures \\
\hline CCaL & CCaL3D (6) & CCaL 7D (6) & CCaL14D (6) & CCa + laparotomy \\
GLNL & GLNL3D (6) & GLNL 7D (6) & GLNL14D (6) & GLN + laparotomy \\
OKGL & OKGL3D (6) & OKGL7D (6) & OKGL14D (6) & OKG + laparotomy \\
CCaH & CCaH3D (6) & CCaH7D (6) & CCaH14D (6) & CCa + hepatectomy (70\%) \\
GLNH & GLNH3D(6) & GLNH7D (6) & GLNH14D (6) & GLN + hepatectomy (70\%) \\
OKGH & OKGH3D(6) & OKGH7D (6) & OKGH14D (6) & OKG + hepatectomy (70\%) \\
\hline
\end{tabular}

$\mathrm{CCa} \mathrm{L}$ - rats submitted to surgical trauma (laparotomy) receiving CCa; GLNL - rats submitted to surgical trauma (laparotomy) receiving GLN; OKGL - rats submitted to surgical trauma (laparotomy) receiving OKG; $\mathrm{CCaH}$ - rats submitted to $70 \%$ hepatectomy receiving CCa; GLNL - rats submitted to $70 \%$ hepatectomy receiving GLN; OKGL - rats submitted to $70 \%$ hepatectomy receiving $\mathrm{OKG} ; 3 \mathrm{D} / 7 \mathrm{D} / 14 \mathrm{D}$ - samples collected on the $3^{\text {rd }}, 7^{\text {th }}$ and $14^{\text {th }}$ day post laparotomy or $70 \%$ hepatectomy. 


\section{Drugs}

Drugs used in the study were purchased from Nutrimed Industrial Ltda, Fortaleza, Brazil (Nutri Protein Nutrimed and L-glutamine), Chiesi S.A, Courbevoie, France (Cétornan - OKG), Promega Corporation, Promega Biotecnologia do Brasil, Ltda, Sao Paulo, Brazil (M-MLV Reverse Transcriptase), Life Technologies, New York, USA (Invitrogen ${ }^{\mathrm{TM}}$ ), Sigma-Aldrich Corp.(Sao Paulo, Brazil) $\mathrm{SyBr}$ Green ${ }^{\mathrm{TM}}$.

\section{Surgical procedure}

Anesthesia was induced with an intramuscular injection of ketamine hydrochloride $(50 \mathrm{mg} / \mathrm{kg})$ and xylazine $(10 \mathrm{mg} / \mathrm{kg})$. The anesthetic regimen was the same throughout the experiment. At the end of three, seven or 14 days as scheduled, the animals were anesthetized for sample collection ( $1.0 \mathrm{ml}$ of arterial blood and $1.0 \mathrm{~g}$ of liver tissue). Another small fragment of liver $(150 \mathrm{mg})$ was individualized to be processed with specific reagents for analysis and quantification of malate dehydrogenase enzymes using the real-time PCR (polymerase chain reaction) methodology.

\section{Laboratory procedures}

Real-time PCR was used for quantification of malate dehydrogenase enzymes. In brief, $150 \mathrm{mg}$ of liver tissue was homogenized in $1 \mathrm{ml}$ of Trizol (Invitrogen ${ }^{\mathrm{TM}}$ ), compound containing phenol and guanidine thiocyanate. Next, $200 \mu \mathrm{l}$ of chloroform was added to $1 \mathrm{ml}$ of the homogenate. After centrifugation and separation of the phases, the RNA retained in the aqueous phase was transferred to another tube containing $500 \mu 1$ of isopropyl phenol alcohol. After spinning, the liquid was discarded and the pellet (dehydrated RNA) was rehydrated with $1 \mathrm{ml}$ of $75 \%$ ethanol and $50 \mu \mathrm{l}$ of UltraPure ${ }^{\mathrm{TM}}$ DEPC-treated Water to 0.01 and stored at $-80^{\circ} \mathrm{C}^{12}$. The production of cDNA was performed in 02 subsequent reactions. Reaction: 1 Oligo dT (Invitrogen $\left.{ }^{\mathrm{TM}}\right)(0.5 \mu \mathrm{g}$ $\mu \mathrm{l})-1 \mu \mathrm{L}$; Total RNA - $1 \mu \mathrm{L}$; dNTP Mix (Invitrogen ${ }^{\mathrm{TM}}$ ) $(1 \mathrm{~mm})-10$ $\mu \mathrm{l}$; sterile $\mathrm{H} 2 \mathrm{O}-1 \mu \mathrm{L}$. Reaction 2: First-Stand Buffer $5 \mathrm{x}-4 \mu \mathrm{l}$; Dithiothreitol (DTT) 0.1 M-2 $\mu \mathrm{l}$; M-MLV Reverse Transcriptase 1 $\mu \mathrm{L}$. The resulting solutions were stored at $-20^{\circ} \mathrm{C}$. As soon as the
CDNA was defrosted, glyceraldehyde 3-phosphate dehydrogenase $(\mathrm{GAPDH}), \mathrm{MDH} 1$ e $\mathrm{MDH} 2(3.6 \mu \mathrm{L})$ forward and reverse primers were added as well as other components (Sigma-Aldrich $\mathrm{SyBr}$ Green $^{\mathrm{TM}} 10 \mu \mathrm{L}$, cDNA 10 ng e sterile $\mathrm{H}_{2} \mathrm{O} 1 \mu \mathrm{L}$ ) before taking the mixture to the thermal cycler for initiation of PCR reaction ${ }^{13,14}$. Each test was conducted in triplicate and the final result was obtained by calculating the average of these results. The final values were obtained considering the calculations of delta threshold cycle $\left(\mathrm{C}_{\mathrm{T}}\right)$ value $\underset{\mathrm{T}}{(\Delta \mathrm{C})}$ and delta/delta $\mathrm{C}_{\mathrm{T}}{ }_{\mathrm{T}}^{(\Delta \Delta \mathrm{C})} \mathrm{v}_{\mathrm{T}}$ values ${ }^{15,16}$. Relative enzymes expression was calculated by $2^{-\Delta \Delta C}$ method using the threshold cycle $\left(\mathrm{C}_{\mathrm{T}}\right)$ value for normalization ${ }^{15,16}$. The extracted RNA quantification was carried out spectrophotometrically GeneQuant Pro $^{\mathrm{TM}}$ - Amersham Biosciences Corp NJ, USA) measuring the absorbance index at $260 \mathrm{~nm}$ and $280 \mathrm{~nm}$ wavelengths. Values greater than 1.6 were considered valid ${ }^{17}$.

\section{Statistical analyses}

To ensure the appropriateness of parametric testing, all data were examined for normality, using Kolmorogov-Smirnov test (with Dalal-Wilkins Lilliefor P Value). Data (expressed as mean \pm standard deviation) were examined for significance using ANOVA followed by Tukey multiple comparisons test. GraphPad Prism 4.0 (GraphPad Software, San Diego, California, USA, www.graphpad.com) was used for statistical analysis and graphics design. Values of $\mathrm{p}<0.05$ were accepted as statistically significant.

\section{Results}

MDH1 and MDH2 relative gene expression (RGE) was calculated by $2-^{\Delta \Delta \mathrm{Ct}}$ method using the Ct value for normalization ${ }^{15}$. No differences were found in MDH1 RGE in rats submitted to laparotomy only when comparing the animals treated with $\mathrm{CCa}$, GLN or OKG. Also, no significant differences were found in $\mathrm{MDH} 2$ expression in rats submitted to $70 \%$ hepatectomy and treated with OKG. However, these differences were greater in animals treated with GLN after three, seven and 14 days posthepatectomy compared with rats treated with CCa. Calculated values for days three, seven and 14 are presented in Tables 2 and 3, Figure 1. 
TABLE 2 - Liver enzyme MDH1 calculated values $\left(\Delta \mathrm{C}_{\mathrm{T}} \Delta \Delta \mathrm{C}_{\mathrm{T}}\right)$ on the $3^{\text {rd }}, 7^{\text {th }}$ and $14^{\text {th }}$ day of the experiment.

\begin{tabular}{|c|c|c|c|c|c|c|c|c|c|}
\hline \multirow{3}{*}{$\mathbf{T x}$} & \multicolumn{3}{|c|}{3 days } & \multicolumn{3}{|c|}{7 days } & \multicolumn{3}{|c|}{14 days } \\
\hline & \multicolumn{2}{|c|}{$\Delta \mathrm{Ct}$} & \multirow{2}{*}{$\frac{\Delta \Delta C t}{H E P}$} & \multicolumn{2}{|c|}{$\Delta \mathbf{C t}$} & \multirow{2}{*}{$\frac{\Delta \Delta C t}{H E P}$} & \multicolumn{2}{|c|}{$\Delta \mathbf{C t}$} & $\Delta \Delta C t$ \\
\hline & LAP & НЕР & & LAP & HEP & & LAP & HEP & HЕР \\
\hline CCA & -7.363 & -1.368 & 5.995 & 0.012 & -2.210 & -2.222 & -5.700 & -7.956 & -2.256 \\
\hline $\mathrm{OKG}$ & -2.375 & -1.690 & 0.685 & 0.802 & -1.757 & -2.558 & -0.653 & -0.905 & -0.251 \\
\hline GLN & -2.733 & -5.093 & -2.361 & -1.414 & -4.722 & -3.307 & -2.137 & -5.099 & -2.963 \\
\hline
\end{tabular}

$\mathrm{Tx}=$ Treatment $\quad \mathrm{CCA}=$ Calcium caseinate; $\mathrm{OKG}=$ ornithine alpha-ketoglutarate; $\mathrm{GLN}=$ Glutamine; $\mathrm{LAP}=$ Laparotomy; HEP= Hepatectomy. The $\Delta$ Cts were obtained by normalization with GAPDH gene. The $\Delta \Delta \mathrm{Cts}$ were obtained using data from laparotomy animals as calibrator

TABLE 3 - Liver enzyme MDH2 calculated values $\left(\Delta \mathrm{C}_{\mathrm{T}} \Delta \Delta \mathrm{C}_{\mathrm{T}}\right)$ on the $3^{\text {rd }}, 7^{\text {th }}$ and $14^{\text {th }}$ day of the experiment.

\begin{tabular}{|c|c|c|c|c|c|c|c|c|c|}
\hline \multirow{3}{*}{$\mathbf{T x}$} & \multicolumn{3}{|c|}{3 days } & \multicolumn{3}{|c|}{7 days } & \multicolumn{3}{|c|}{14 days } \\
\hline & \multicolumn{2}{|c|}{$\Delta \mathbf{C t}$} & \multirow{2}{*}{$\frac{\Delta \Delta \mathbf{C t}}{\mathbf{H E P}}$} & \multicolumn{2}{|c|}{$\Delta \mathbf{C t}$} & \multirow{2}{*}{$\frac{\Delta \Delta \mathbf{C t}}{\mathbf{H E P}}$} & \multicolumn{2}{|c|}{$\Delta \mathbf{C t}$} & \multirow{2}{*}{$\frac{\Delta \Delta \mathbf{C t}}{\text { HEP }}$} \\
\hline & LAP & HEP & & LAP & HEP & & LAP & HEP & \\
\hline CCA & -7.475 & -6.707 & 0.768 & -3.885 & -5.845 & -1.960 & -6.763 & -6.617 & 0.146 \\
\hline OKG & -5.045 & -2.322 & 2.723 & -3.100 & -1.882 & 1.218 & -1.658 & -3.201 & -1.543 \\
\hline GLN & -4.735 & -8.693 & -3.958 & -4.219 & -7.492 & -3.272 & -3.325 & -6.141 & -2.816 \\
\hline
\end{tabular}

$\mathrm{Tx}=$ Treatment $\mathrm{CCA}=$ Calcium caseinate; $\mathrm{OKG}=$ ornithine alpha-ketoglutarate; $\mathrm{GLN}=$ Glutamine; LAP= Laparotomy; HEP= Hepatectomy. The $\Delta$ Cts were obtained by normalization with GAPDH gene. The $\Delta \Delta$ Cts were obtained using data from laparotomy animals as calibrator.
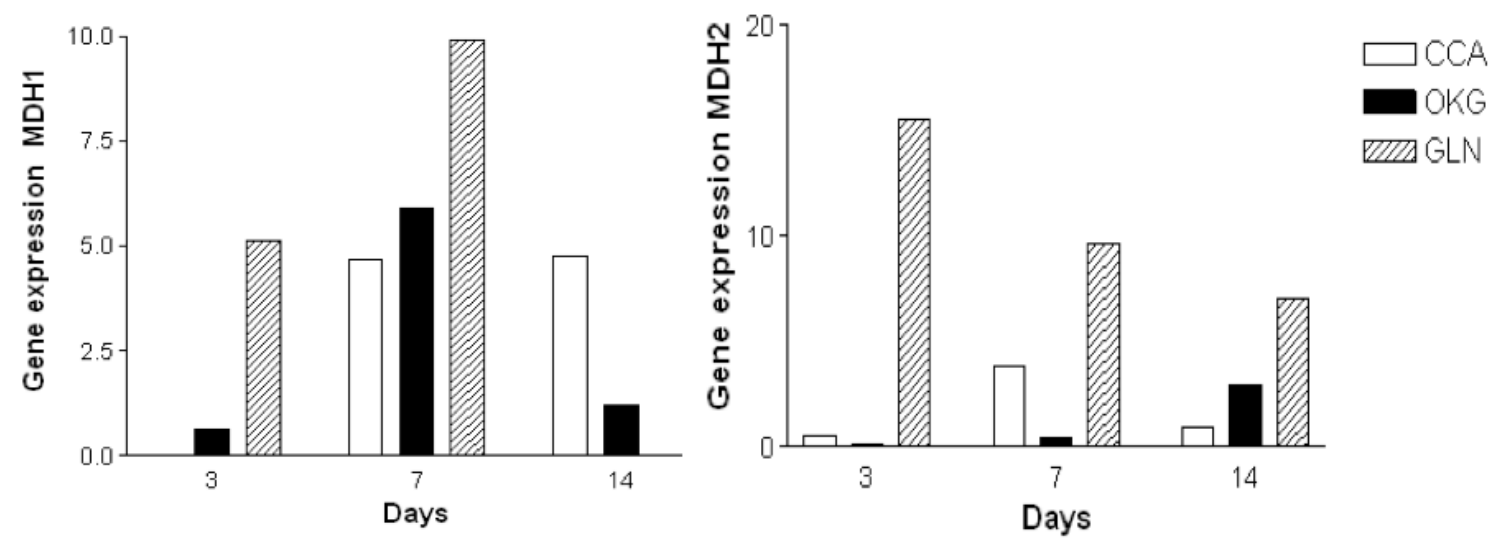

FIGURE 1 - Liver enzymes $(M D H 1, M D H 2)$ relative gene expression $\left(2-_{-}^{\Delta \Delta C}\right)$ on the $3^{\text {rd }}, 7^{\text {th }}$ and $14^{\text {th }}$ day of the experiment. Results were obtained using the 2- $\Delta \Delta$ CT calculation (Livak and Schimittgen, 2001). MDH1 Relative Gene Expression (RGE) was greater on days 3 and 7, compared with CCA. MDH2 RGE was greater in all timepoints, compared with CCA in GLN-treated rats.

\section{Discussion}

Analysis of data from real-time quantitative PCR experiments may be carried out using different methods. The two most commonly used methods are absolute quantification and relative quantification. The first method (absolute quantification) determines the input copy number, usually by relating the PCR signal to a standard curve. The second method (relative quantification) relates the PCR signal of the target transcript in a treatment group to that of another sample such as an untreated control ${ }^{15}$. A reliable method to analyze the relative changes in gene expression from real-time quantitative PCR experiments is known as the $2-{ }^{\Delta \Delta C t}$. This method may be used to calculate relative changes in gene expression determined from real-time quantitative PCR experiments ${ }^{15}$.
According to Livak and Schimittgen ${ }^{15}$, the endpoint of real-time PCR analysis is the threshold cycle of $\mathrm{C}_{\mathrm{t}}$. Considering that $\mathrm{C}_{\mathrm{t}}$ is determined from a log-linear plot of the PCR signal versus the cycle number, the value obtained is an exponential and not a linear term. Therefore, any statistical presentation using the raw $\mathrm{CT}$ values should be avoided. Based on the assumptions, the 2 $-\mathrm{C}_{\mathrm{t}}$ calculation was used here for results analyses.

Liver regeneration mechanism has been extensively studied. Hepatic cells are normally quiescent. However, after partial hepatectomy approximately $95 \%$ of hepatic cells rapidly re-enter the cell cycle. In the rat liver, the rate of DNA synthesis in hepatocytes begins to increase after about 12 hours and peaks around 24 hours. Non-parenchymal tissues have a later start for DNA synthesis. 
Subsequent levels of DNA synthesis in hepatocytes are lower, as complete restoration of liver mass requires an average of $\sim 1.6$ cycles of replication in all cells ${ }^{18}$. Most of the increase in liver mass has occurred by three days after partial hepatectomy and mass restoration is complete in 5-7 days ${ }^{19}$.

In order to maintain the metabolic homeostasis during regeneration the liver undergoes an adaptive response to regulate the differentiated functions of the hepatocyte. This is accomplished by the interplay between different sets of transcription factors, induced by the regenerative response $\mathrm{e}^{20}$. Liver regeneration requires large amounts of energy to take place. One of the mechanisms involved in supplying energy to the hepatocyte is the autophagy seen in acute liver injury. However, hyperactivation of autophagy induces cell death, and the necrosis rate is actually a predictor of liver failure ${ }^{21}$.

The malate/aspartate shuttle is the major pathway by which cytosolic reducing equivalents from NADH can enter the mitochondria and be oxidized ${ }^{22}$. MDH1 and MDH2 enzymes play important roles in the Krebs cycle for energy production through aerobic respiration ${ }^{9}$. The malate-aspartate shuttle translocates electrons produced during glycolysis across the semipermeable inner membrane of the mitochondrion to the electron transport chain via NADH to generate ATP. The shuttle system is required since the mitochondrial inner membrane is impermeable to NADH. To circumvent this, malate carries the reducing equivalents across the membrane ${ }^{23}$.

This study has demonstrated that the use of GLN in partially hepatectomized rats promotes an over expression of MDH1 and MDH2 enzymes during liver regeneration. The explanation for the these findings is the same already duly proven in previous study ${ }^{23}$ increased GLN availability enhances the malate-aspartate shuttle requiring an up-regulation of gene expression of both MDH1 and MDH2 enzymes.

The results presented here show that GLN supplementation in this model of partial hepatectomy has beneficial effects in liver regeneration considering that there was an up-regulation of the MDH1 and MDH2 gene expression in rats treated with GLN. On the other hand, the use of OKG did not lead to an overexpression of MDH1/MDH2.

\section{Conclusions}

Glutamine has beneficial effects in experimental liver regeneration by promoting an up-regulation of MDH1 and MDH2 gene expression. The use of ornithine alpha-ketoglutarate does not change MDH1 and MDH2 gene expression in experimental liver regeneration in rats.

\section{References}

1. Fujiyoshi M, Ozaki M. Molecular mechanisms of liver regeneration and protection for treatment of liver dysfunction and diseases. $\mathrm{J}$ Hepatobiliary Pancreat Sci. 2011 Jan;18(1):13-22. doi: 10.1007/ s00534-010-0304-2.

2. Riehle KJ, Dan YY, Campbell JS, Fausto N. New concepts in liver regeneration. J Gastroenterol Hepatol. 2011 Jan;26 Suppl 1:203-12. doi: 10.1111/j.1440-1746.2010.06539.x.

3. Holecek M. Nutritional modulation of liver regeneration by carbohydrates, lipids, and amino acids: a review. Nutrition. 1999 Oct;15(10):784-8. PubMed PMID: 10501293.

4. Birkhahn RH, Awad S, Thomford NR. Parenteral monoacetoacetin and liver regeneration interaction after partial hepatectomy in the rat. JPEN J Parenter Enteral Nutr. 1994 May-Jun;18(3):219-24. PubMed PMID: 80649956.

5. Coudray-Lucas C, Le Bever H, Cynober L, De Bandt JP, Carsin H. Ornithine alpha-ketoglutarate improves wound healing in severe burn patients: a prospective randomized double-blind trial versus isonitrogenous controls. Crit Care Med. 2000 Jun;28(6):1772-6. PubMed PMID: 10890617.

6. Jeevanandam M, Holaday NJ, Petersen SR. Ornithine-alphaketoglutarate $(\mathrm{OKG})$ supplementation is more effective than its component salts in traumatized rats. J Nutr. 1996 Sep;126(9):214150.PubMed PMID: 8814202.

7. Nurjhan N, Bucci A, Perriello G, Stumvoll M, Dailey G, Bier DM, Toft I, Jenssen TG, Gerich JE. Glutamine: a major gluconeogenic precursor and vehicle for interorgan carbon transport in man. J Clin Invest. 1995 Jan;95(1):272-7. PubMed PMID: 7814625.

8. Yoshida S, Yunoki T, Aoyagi K, Ohta J, Ishibashi N, Noake T, Kakegawa T. Effect of glutamine supplement and hepatectomy on DNA and protein synthesis in the remnant liver. J Surg Res. 1995 Oct;59(4):475-81. PubMed PMID: 7564320.

9. Bourneuf E, Hérault F, Chicault C, Carré W, Assaf S, Monnier A, Mottier S, Lagarrigue S, Douaire M, Mosser J, Diot C. Microarray analysis of differential gene expression in the liver of lean and fat chickens. Gene. 2006 May 10;372:162-70. PubMed PMID: 14965116.

10. Lo AS, Liew CT, Ngai SM, Tsui SK, Fung KP, Lee CY, Waye MM. Developmental regulation and cellular distribution of human cytosolic malate dehydrogenase (MDH1). J Cell Biochem. 2005 Mar 1;94(4):763-73. PubMed PMID: 11225055.

11. Dupourque D, Kun E. Malate dehydrogenases of ox kidney. 2. Two substrate kinetic and inhibition analyses. Eur J Biochem. 1969 Jan;7(2):247-52. PubMed PMID:4303911.

12. Chomczynski P, Sacchi N. Single-step method of RNA isolation by acid guanidinium thiocyanate-phenol-chloroform extraction. Anal Biochem. 1987 Apr;162(1):156-9. PubMed PMID: 2440339.

13. Gibson UE, Heid CA, Williams PM. A novel method for real time quantitative RT-PCR. Genome Res. 1996 Oct;6(10):995-1001. PubMed PMID: 8908519

14. Heid CA, Stevens J, Livak KJ, Williams PM. Real time quantitative PCR. Genome Res. 1996 Oct;6(10):986-94. PubMed PMID: 8908418

15. Livak KJ, Schmittgen TD. Analysis of relative gene expression data using real-time quantitative PCR and the 2(-Delta Delta C(T)) Method. Methods. 2001 Dec;25(4):402-8. PubMed PMID: 11846609.

16. Kubista M, Andrade JM, Bengtsson M, Forootan A, Jonák J, Lind K, Sindelka R, Sjöback R, Sjögreen B, Strömbom L, Ståhlberg A, Zoric N. The real-time polymerase chain reaction. Mol Aspects Med. 2006 Apr-Jun;27(2-3):95-125. PubMed PMID: 16460794.

17. Sambrook J, Russel W. Molecular cloning - A laboratory manual. 3ed. New York: Cold Spring Harbor Laboratory Press; 2001. 
18. Sigal SH, Rajvanshi P, Gorla GR, Sokhi RP, Saxena R, Gebhard DR Jr, Reid LM, Gupta S. Partial hepatectomy-induced polyploidy attenuates hepatocyte replication and activates cell aging events. Am J Physiol. 1999 May;276(5 Pt 1):G1260-72. PubMed PMID: 10330018.

19. Grisham JW. A morphologic study of deoxyribonucleic acid synthesis and cell proliferation in regenerating rat liver; autoradiography with thymidine-H3. Cancer Res. 1962 Aug;22:842-9. PubMed PMID: 13902009.

20. Costa RH, Kalinichenko VV, Holterman AX, Wang X. Transcription factors in liver development, differentiation, and regeneration. Hepatology. 2003 Dec;38(6):1331-47. PubMed PMID: 14647040.

21. Rautou PE, Mansouri A, Lebrec D, Durand F, Valla D, Moreau R. Autophagy in liver diseases. J Hepatol. 2010 Dec;53(6):1123-34. doi: 10.1016/j.jhep.2010.07.006.

22. McKenna MC, Waagepetersen HS, Schousboe A, Sonnewald U. Neuronal and astrocytic shuttle mechanisms for cytosolicmitochondrial transfer of reducing equivalents: current evidence and pharmacological tools. Biochem Pharmacol. 2006 Feb 14;71(4):399-407. PubMed PMID: 16368075.

23. Shi Q, Gibson GE. Up-regulation of the mitochondrial malate dehydrogenase by oxidative stress is mediated by miR-743a J Neurochem. 2011 Aug;118(3):440-8. doi: 10.1111/j.14714159.2011.07333.x

\section{Correspondence:}

Prof. Sergio Botelho Guimarães

Rua Professor Costa Mendes, $1608 / 3^{\circ}$ andar

60430-140 Fortaleza - CE Brasil

Tel.: (55 85)3366-8083

Fax: (55 85)3366-8064

sergiobotelho@terra.com.br

Received: Jan 14, 2014

Review: March 13, 2014

Accepted: April 17, 2014

Conflict of interest: none

Financial source: none

${ }^{1}$ Research performed at Experimental Surgical Research Laboratory (LABCEX), Faculty of Medicine, Department of Surgery, Federal University of Ceara (UFC) and Sobral Biotechnology Nucleus, FortalezaCE, Brazil. Part of PhD degree thesis, Postgraduate Program in Surgery, Federal University of Ceara (UFC), Tutor: Prof. Dr. Sergio Botelho Guimaraes. 